\title{
La "artelización" del paisaje: Perspectiva de los movimientos de la pintura costarricense ${ }^{1}$
}

\begin{abstract}
Resumen
El artículo se centra en la percepción que tenemos las personas del paisaje, desde la apreciación de la obra pictórica, y en los aspectos más relevantes sobre este tema en nuestro país; por lo tanto, en la historia de la pintura costarricense. Sin considerar la amplia variedad de implicaciones que el tema tiene en las diferentes disciplinas que lo estudian.
\end{abstract}

Palabras claves: Artelización, cultura, idealización, paisaje, percepción.

\section{Luis Alonso Rojas Herra.}

Licenciado en arquitectura de Universidad Veritas. Cursa actualmente el Posgrado en

Paisajismo y Diseño de sitio de la Universidad de Costa Rica (UCR). Labora como profesional independiente en consultoría de diseño arquitectónico y docente universitario en la Universidad Hispanoamericana y ULACIT. Irojasherra@gmail.com

\section{Introducción}

"Paisaje" se puede definir ampliamente como el aspecto visible y perceptible del espacio, porque implica la existencia de un observador que contemple esa porción desde un punto de vista determinado. Se trata de un tema complejo e interdisciplinario del cual se ha dicho mucho.

La percepción del paisaje está fuertemente ligada a la cultura, en el sentido más amplio del término; cada periodo de la historia ha creado sus propios estereotipos de paisaje, con sus símbolos y formas de interpretación basados en la obra pictórica. 
La pintura del paisaje se puede interpretar de forma general como un dinámico código de símbolos que nos hablan de la cultura del pasado, presente y futuro. La lectura de la semántica de los cuadros paisajísticos se refiere a la interpretación de esos símbolos e intenciones del artista, ligados estrechamente a la cultura que los vio nacer.

Decodificar la ideología del paisaje por medio de la obra pictórica como si fuera un sistema de signos y de símbolos nos permite entender el paisaje como un elemento complejo, pero al mismo tiempo como un texto, donde queda inscrit su percepción a través del tiempo.

\section{Percepción del paisaje}

El paisaje es el resultado visible de la interacción entre los compontes de la naturaleza (todos los elementos que se ven en y desde la superficie terrestre), la acción humana (que modifica el territorio) y las mentes de las personas que la pueblan. El paisaje es el resultado de la construcción de cada sociedad que busca señales, hitos yesde esta perspectiva, "paisaje" (o el conjunto de estos) sería la manifes tón esta perspectiva, "paisaje" (o el conjunto de estos) seria la manifesta evolución pro o tangible de la mezcla de varios factores. el primero de ellos, la evolución propia de la naturaleza, que a través del tiempo se ha encargado los rís que lo atravisan, la formación de las costas y de establecer la peas de los ríos que lo atraviesan, la formación de las costas y de estable sumado pasto el factor de la accín humas.

Sumado a esto, el factor de la accion humana que se ha encargado de ir transcidad para alterary agotar el de la historia, en función de sucín de lante capay sus recursos. El hombre ha modificado y sus recursos. El hombe ha modificado el aspecto y la forma del territorio que sus extensas redes de carretas que los comunican entre ellos, y sus grandes obras sus exfraestructura. Muchas de ( cueciz perdurar durante el paso del tiempo convirtiénd ose en milenios. Y por último, todas las manifestaciones culturales y sus variadas form

Y por último, todas las manifestaciones culturales y sus variadas formas de proyección que trabajan en la búsqueda de expresiones de una identidad a lo ferencias que permitan vincular los lugares que habitamos y los sucesos de época. A su vez, cada cultura dará diversas lecturas del paisaje en función de los grupos sociales que la integran.

Además de las percepciones del paisaje desde el exterior, existe otra aproximación al paisaje que lo estudia como una construcción mental que surge cuando artista interpreta el medio que lo rodea, basándose principalmente en su expe riencia personal y la cultura de la que participa y lo plasma en su obra pictórica, a este tipo de percepción le llamaremos, en adelante, "artelización". a pintura del entorno paisajístico es un fragmento de ese mundo anteriormente descrito, pero, a su vez, es la construcción del artista, la composición de ese mundo expresada por una forma de ver, un punto de vista, al mismo tiempo que representa la proyección cultural de una sociedad en un espacio determinado. Según este punto de vista, el paisaje existe desde el sentido de la vista de artista que es transmitido al espectador cuando contempla la escena; en este método de percepción las variables de espacio y tiempo son controladas según la intención del artista.
Este enfoque, en la interpretación del paisaje, nos lleva a la apreciación estética y simbólica del paisaje, en la que se busca respuesta a cuestiones tales como si la belleza de un paisaje es un término absoluto, o si pueden establecerse normas - reglas en la percepción de los paisajes.

El paisaje, en este caso, se analiza desde el lienzo, por lo que su expresión corresponde a un plano. Hay que tomar en cuenta que no se presenta como una interpretación estricta de la naturaleza o el paisaje, como en el caso de las fotografías o ilustraciones literales de un paisaje en particular.

Al comprender que detrás de la obra pictórica existe una intención del artista, el lienzo nos puede transportar a la creación de una realidad que puede ser ignorada por el ojo humano.

En la historia de la pintura, el paisaje fue adquiriendo poco a poco, cada vez, más relevancia, desde su aparición como fondo de escenas de otros géneros, como la pintura de historia o el "Pasaj" como en la pina dado al género pictorico que representa Dentro de la je arbolitios y bosques.

Duperior dugar muy bajo, suptura que representa objetos sin vida en un espacio determina, es una mas de caza, frutas, flores, utensilios de cocina, de mesa o de casa, antigüedades, etc.)

La representación pictórica de los elementos naturales en la época precolombina de Costa Rica se concebía por medio de la imitación de las mismas, las formas predominantes eran abstractas y muy sencillas, enfocadas en represenaisladas del paisaje, con un fuerte contenido simbólico.

No fue sino hasta la entrada de los conquistadores españoles que al arte cosarricense comenzó a imitar las grandes obras de los artistas internacionales, lo cual generó, al tomar como base las intenciones sociales de la burguesia y las políticas del estado, una fuerte influencia de parte de los artistas nacionales por

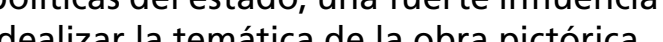

A pesar de esta evidente influencia durante toda la fase de colonización, las obras nacionales lograron mantener ciertos rasgos en cuestión de técnica y utilización de materiales que denotaron un evidente principio de identidad artística en las obras.

La historia del arte, en costa Rica es muy breve comparada con la milenaria radición artística del continente europeo por ejemplo. Con escasos no más de 100 años, nuestra historia se circunscribe en bloques y movimientos de artistas.

\section{Los fundadores: El mito de la blancura}

La primera generación corresponde a los fundadores, con la llegada al país del español Tomás Povedano y la inauguración, a su cargo, de la Facultad de Bellas Artes de la Universidad de Costa Rica, el 12 de marzo de 1897. Entre sus mayores representantes estuvieron Emil Spam، Enrique Echandi, Juan Rafael Chacón y Juan Ramón Bonilla.

La Escuela de Artes Plásticas en sus inicios se proyectó como una escuela de mujeres burguesas que se reunían a pintar elementos descontextualizados como flores, frutas o elementos inertes propios del neoclásico del género bodegón, anteriormente mencionado. En nuestro país, la pintura fue considerada, en sus 
inicios, una disciplina dominada exclusivamente por el género femenino, las mencionadas damas de sociedad, quienes eran las que podían obtener el tiempo y el acceso económico a este tipo de educación.

Las obras pictóricas de este periodo inicial cumplen con fin claramente académico y poseen un carácter idealizante, por lo que, en consecuencia, a este primer bloque se le acusó fuertemente por hacer pintura que no tenía ningun vinculacion con el ambiente nacional y nuestra verdadera identidad.

Un claro ejemplo de la idealización se da con el desarrollo agrícola, a finales del periodo de la colonia, cuando la sociedad burguesa se empezó a enriquecer partir de la exportación de productos agricolas como el café y el banano; de esta forma, la nueva capital de Costa Rica, San Jose, cambia su aspecto de humilde aldea por una imagen más urbana. Las primeras intenciones de ciudad afloran

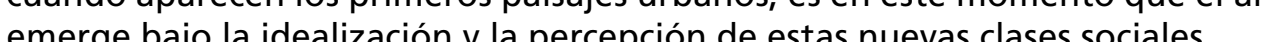

e

Aparece el "mito de la blancura", forma en que se le denomina el proposito de los burguto de la bitar las sociedades europeas. Esta sítuación se vuelve evidente con el surgimiento del desprecio a la obra de autorla nacional, cóno el caso de Juan Ramón Bonilla y su miserablemente hoy en día en el Teatro Nacional, olvidada en el in Consiente de la sociedad, fue considerada en su momento por la critica mundial como divinamente bella perocon desdén en su propio pars.

Foto 1. El mejor y más claro ejemplo de esta situación es la famosa pintura del artista

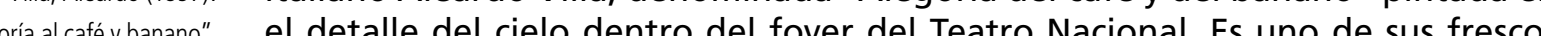
más conocidos, utilizado también, en su momento, como ilustración gráfica de
billete de cinco colones.
El cuadro alude al comercio de los dos importantes productos de exportación com/2014/06/09/2legoriade la época que hicieron de Costa Rica un país "próspero", representa una metáfora y un tributo a la clase burguesa agroexportadora y promotora en torno a del 2015. la idea de la blancura.

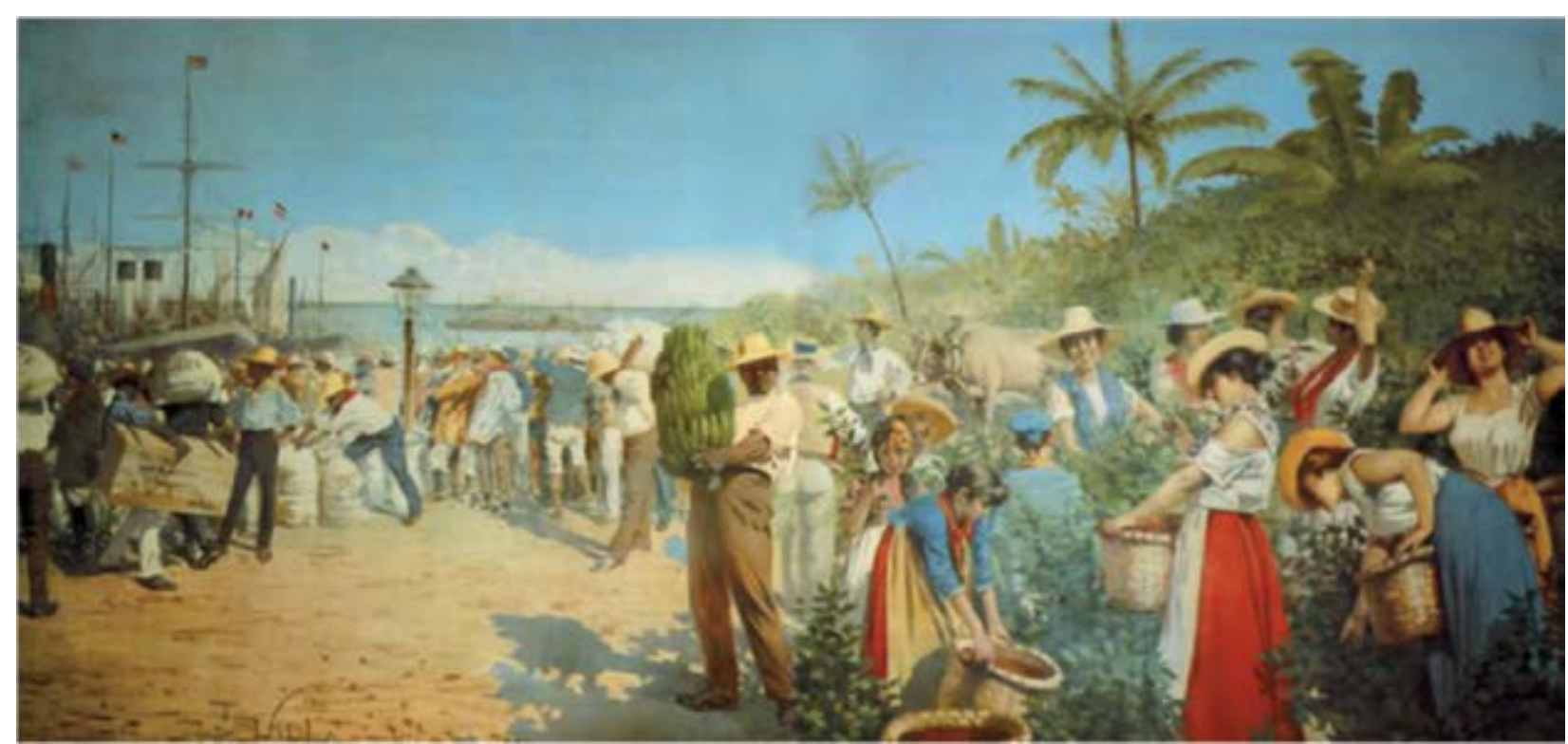

La escena se contextualiza en la zona atlántica del país. El caribe fue el principal territorio de desarrollo de estas economías; en el cuadro se muestran recolectoras de café en estado de felicidad, llevando a cabo sus labores, claramente lejos de la realidad de la práctica de recolección de café; se representan ganaderos, y un hombre "afrocostarricense", como personaje principal, cargando, de forma equivocada, un racimo de banano en un puerto con pasajeros y cargadores llevando costales de café.

A nivel simbólico, el personaje central representa la clase trabajadora, es un "peón", socialmente excluido, desligado de su papel o de su vínculo con la construcción del propio ferrocarril y, además, nunca se le va a identificar el nexo con lo rentidud del pueblo caribeño. El esteretipo del "afrocostanricense", según lo reproduce Aleardo Villa, como cargador de bananos, conlleva, además del social pobre.

Según explica Alexander Jiménez: "Hay también estrategias geográficas. Si se asentía a la imagen de un pais blanco era en parte porque, dejando de lado el asunto del mestizaje El cuadro es, ensínismo, una paradoja. En paste (2008, p. 7 ).

作 liza por como

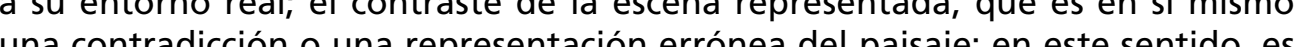
imposible que en la zona costera del atlántico se dieran cultivos de café propios mposible que en la zona costera

La fama que alcanzo el billete de cinco colones, mencionado anteriormente, lo ha llevado a ser nombrado hoy uno de los más bellos del mundo por la numismática. Este hecho, junto con la reproducción en masa del paisaje del cuadro en el billete, les vendió la idea de un paisaje rural equivocado a muchas personas que no han percibido el país y observan el billete, el cual se había convertido en una ventana que inspiraba a conocer nuestro pequeño territorio de América Central. No sería la primera vez que un método de reproducción masiva de la obra pictórica popularizara la percepción del paisaje en las mentes de los ciudadanos. Sussy Vargas, curadora del Teatro Nacional, en el año 2005 declaró para una entrevista del diario La Nación que "se considera a Fausto Pacheco como el artista responsable de popularizar el paisaje. Ya que su obra se imprimió a nivel masivo en serigrafía por primera vez en el pás" (Dorian Díaz "Exposición muestra lo menos conocido de Fausto Pacheco", 2005, sección Aldea global, La Nación). De esta forma las personas y familias costarricenses tuvieron acceso a copias de obras de arte a muy bajo costo, con el fin de decorar sus hogares. Por un las se piensa que su aporte fue de ayudar a que el arte tuviera un acercamiento al pueblo, cuando realmente su comercialización difundió la idealización del paisaje onírico (Sussy Vargas, 2005).

A finales del siglo XIX, con la llegada al país de personalidades destacables del ambiente artístico, se empiezan a representar temas como la vida indígena las costumbres del pueblo costarricense y el paisaje, temas que impresionaban a los artistas. Por esta razón, realizaron varias pinturas que muestran la cultura, la historia, el arte y la fisonomía de los indígenas del territorio.

En el caso de la cultura indígena, en su mayoría representan una visión objetiva y seria de la propia cultura aborigen, aunque los personajes son idealizados: se mantiene el mismo déficit perceptual que se da con los negros, campesinos y el paisaje en general. 
Festividad del paisaje: la representación de la realidad que se miraba

El sentimiento nacionalista que se empieza a desarrollar con la nueva intelectualidad de principios de siglo XX (Roberto Brenes Mesén, Joaquín García Monge, Omar Dengo, José María "Billo" Zeledón, entre otros) y las luchas sociales de la época (Morales, 1994) ofrece un marco idoneo a los jóvenes artistas que inician su trabajo en la década de 1930 y desarrollan una nueva sensibilidad. "El indio" Sánchez (1907-1990), Franisco "Paco" Zúñiga (1912-1998) y Nésanue "El indio" Sánchez (1907-1990), Francisco "Paco" Zúniga (1912-1998) y Néstor Ze-

La generación de los 30 (Illamada también "nacionalista") adopta un mayor arraigo a la identidad del pais. En este periodo, grandes artistas lograron extrae la vida y el paisaje de nustra tierra. En la expresión literaria se encontró una de las mayores formas de representacion de la raldad costanicense, el paisaje tos con gran realisma y roflejon contextos, sociedades y valles, etc., son descritos con gra resta regiones de Costa Rica, porque mu

Autores como Carlos Salazar Herrera reflejan en su literatura el sentir y espíritu del pueblo costarricense, sobre todo de las minorias. Sobre la relación entre e personaje y el paisaje, Camacho se refiere al libro "El estilo en los cuentos de
Salazar Herrera", con la siguiente idea: Los personajes de Salazar Herrera son pasivos y débiles. Se impresionan con facilidad por el (Angustias, que es una parte negativa del hume conforma el titulo de la obra (Angustias, que es una parte negativa del humano, y paisajes, que hombre ante la naturasza (el paisaje decide la suerte de los perso derrota del con "El Camino" y "El Temporal". Estos personajes se rinden ante su entorno, y con "El Camino"y (Camacho J.A, 1982, pág. 82).

El papel de la narrativa cumple una función más sobresaliente en el aporte de una identidad nacional: uso del lenguaje popular, rescate coloquial, la inclusión una identidad nacional: uso des una social de la sociedad burguesa.

social de la sociedad burguesa.
Muchos de las descripciones utilizadas en la narrativa de ese periodo utilizan términos que hacen referencia a elementos naturales presentes en nuestros paisajes, demostrando ese vínculo inherente que tenemos con la forma de como sajes, demostrando ese vinculo inherente que tenemos con la forma de como percibimos el paisaje y nuestro estilo de vida, ejemplo de ello es un el siguiente:
"Rosa, aquella morena liberiana, tan simpática, la más inteligente de todas, nos "Rosa, aquella morena liberiana, tan simpatica, la más inteligente de todas, nos "Carne de miseria" de Carmen Lyra (2011, p. 2).

Mientras que en la literatura se trata la descripción de la figura del campesino como un personaje trabajador, que vive en la miseria, desamparado, se recrean las inclemencias de su diario vivir y el mundo hostil en que lo rodea, la obra pictórica no logra superar con éxito el modelo costumbrista heredado del movimiento anterior, donde figuras de las clases sociales menores, como el campesino, siguen siendo estereotipado y pintoresco.

Durante todo el siglo XX hubo un esfuerzo por el artista pictórico costarricense en preservar lo oriundo de nuestras costumbres y formas de socialización, lo

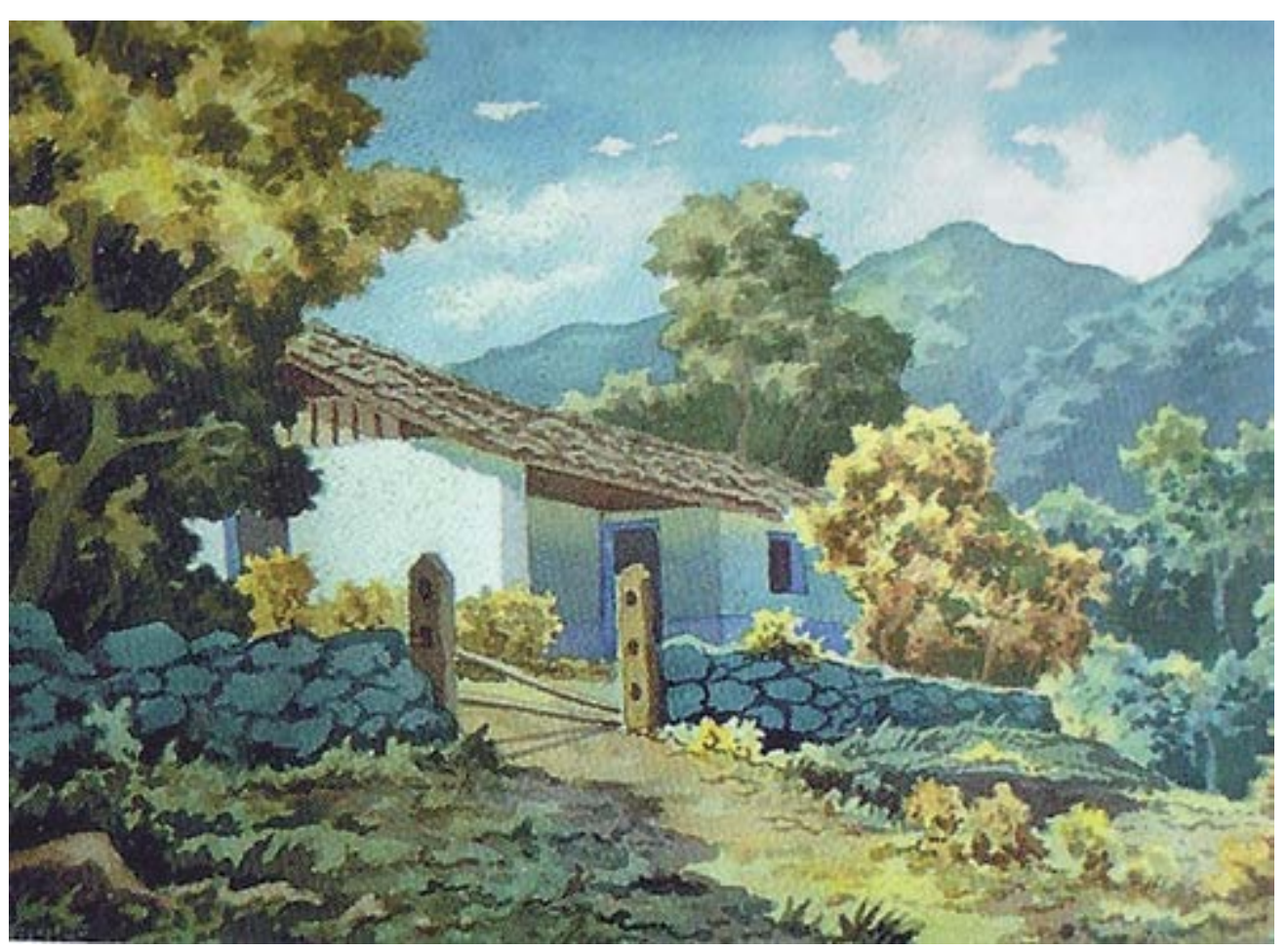

Foto 2. Pacheco, Fausto (sin año), Cosay Tranquera (técrica acuarela) tomada de en Costa Rica", revista de la colección de arte costaricense para niños universidad de Costa Rica.

cual se puede constatar en la rica gama de temáticas y ambientes utilizados en la pintura nacional: la intimidad de interiores campesinos, en las playas, puentes o caminos empedrados, en paisajes brumosos o de arrebatado pintoresquismo tropical. En nocturnos silenciosos, claros amaneceres o quietos paisajes de la tarde, la representación de la pulpería, actividades económicas por medio el trapiche, cafetales, el patrocinio de la herencia indígena, otro tema muy utilizado por nuestros artistas, y por supuesto lo natural visto desde una perspectiva de realismo onírico.

Dentro del ambiente pictórico de esta época, cabe mencionar la labor de Fausto Pacheco, paisajista nato, él inicia la tarea de retratar la realidad nacional a través de la familia, la comunidad, la vida cotidiana. Por lo que se le considera un pintor de tema nacional.

to pintoresco y lo característico: la casa campesina, el árbol conocido, las cercas familiares, las piedras del camino, las montañas, en fin, la tierra costarricense.

Por otra parte, Teodorico Quirós fue de los artistas que incorporaron en el paisaje nacional campestre, siempre verde y soleado, elementos propios de la cultura oriunda; el boyero y la carreta se convierten en personajes que se repiten una y otra vez en las obras costarricenses, la casa de adobe, dentro de un contexto idealizado, la cual tuvo gran importancia también en esa época.

Teodorico Quirós fue Decano de la Facultad de Bellas Artes de la Universidad de Costa Rica desde 1942 hasta 1945. En este corto período introdujo cambios importantes en los planes de estudio, como el dibujo de la figura humana natural y la pintura al aire libre, y fue el responsable de reunir al primer grupo de paisajistas artistas del país. En la información elaborada por la Red Nacional de Investigación para el Museo Nacional de Costa Rica sobre la biografía del artista se dice: 
Quirós crea una vasta e importante obra pictórica del paisaje nacional que le ha merecido un lugar en la historia del arte costarricense. Como arquitecto fue responsable de proyectos públicos y privados. Construyó gran cantidad de iglesias, consideradas de gran valor arquitectónico. Fue uno de los primeros en preocuparse por la conservación de las obras arquitectónicas coloniales. (Biografía
Teodorico Quirós, Vichitex. 2006).

\section{Paisaje no figurativo: la transformación de la realidad que se miraba}

Unas décadas más adelante, en la segunda mitad del siglo XX, el denominado "Grupo de los 8", introduce el arte informalista no figurativo al país, lo que constituye un cambio significativo en el lenguaje de representación de la obra pictórica.

Un claro ejemplo del empleo de este lenguaje se da en varios de los grabados donde el paisaje está ausente de una representación literal del mismo, por el contrario uniza una paleta de colores diferentes a los acostumbrados, verdes azules, con los que re represtaba la naturaleza y el celaje y las formas empleación o mayor ras, de esta forma la pieza artistica adquiere una nueva connotatransmitir su pereveión su contenido. Para el artista cobra mayor importancia tra el paisaje se vuelve un elemento que trasmite una posicion ideologica del artista

En este periodo, el colorido de los cuadros es rico y variado, el artista se permite discurrir en la libre invención del paisaje hasta el naturalismo con sus valores, estableciendo reglas para la percepción del paisaje bajo el dominio de su técnica. Esta nueva sensibilidad, heredada del movimiento nacionalista, capta con simplicidad el entorno y sus personajes (el tipo criollo o campesino) otorgándole Dur recogimiento a ambos.

De este grupo surgen grandes exponentes como Rafael Ángel "Felo" García quien en sus obras de paisaje urbano, mostraba un interés personal que iba más quien en sus obras de paisaje urbano, mostraba un interes personal que iba más alla de representar la realidad sociá del pais. Surob y su implicación social, a peque aborda principalmente lá sar que el factor humano está ausente en todos los cuadros de esta serie, invita dentro de la temática del paisaje urbano.

Esta serie de estética de tugurios creada por Felo García es producto de un serie de inquietudes que alberga en el artista. Propias de su profesión como arquitecto y de su ejercicio en la planificación urbana. No se trata de denuncia social o política, sino de la simple observación de lo cotidiano en su vida como él mismo lo menciona en una entrevista realizada por Ileana García para como torial de la Universidad de Costa Rica para la realización del libro Felo García Arista, gestor, provocador, innovador: Plantea que el problema principal de esta solución habitacional es la salubridad, servicios adecuados, pero encuentra interesante el planteamiento y la solución de convivencia en que se respeta un orden para cohabitar, las puertas y las ventanas permanecen abiertas, sus pertenencias y vestidos están expuestos, no se roban entre los habitantes. Felo García: Arista, gestor, provocador, innovador: p. 37
Por su parte, el artista Fabio Herrera pinta su colección entre rejas, una mirada insatisfecha sobre el problema de la inseguridad social, las violentas transformaciones que ha sufrido el paisaje en consecuencia de esta problemática, en esta serie Ventagramas" de protesta, el autor nos transmite la manera mediante la cual se perciben los paisajes a través de las rejas de la casa. El mismo Fabio Herrera (1997)
se refiere a los cambios constantes que sufre el paisaje día a día:

El paisaje ha cambiado dramáticamente. La semana pasada estaba en Playa Hermosa pintando: antes predominaban los colores verde, rosado y marrón; ahora, los
colores son de luces de neón, carreteras, rótulos - lamenta el pintor- Me siento impulsado a crear arte para atraer poderosamente, satisfacer profundamente $y$ impulsado a crear arte para atraer poderosamente, satisfacer profundam
preservar históricamente los estragos de la humanidad y el medio ambiente.

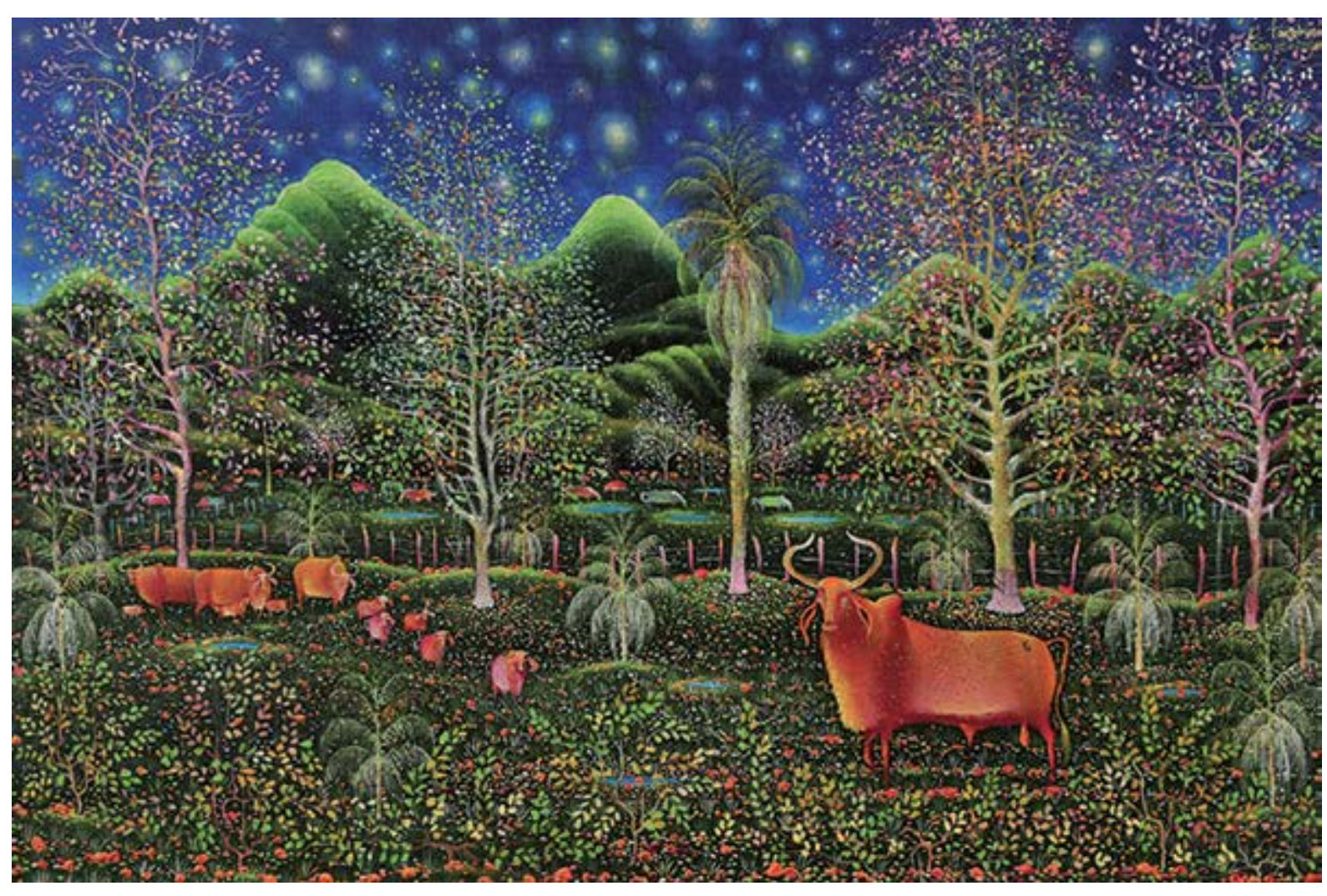

Foto 3. Wong, Isidro (1987), "Toro buey con crías". Recuperado de: http://wwww.nacion.com/ocio/artes/Maestros-paisjaj-Costa-

Rica_0_1436256401.html, consultado el 02 de Mayo del 2015.

Jean Pierre Bergoeing, desde julio de 2005, se desempeña como profesor catedrático en la Universidad de Costa Rica, e imparte cursos de geomorfología, ordenamiento territorial, análisis geográfico, geografía mundial, etc. Desde esta pers-
pectiva sus obras describen un realismo onírico, ya que destacan la naturaleza y los paisajes de los países y regiones que ha visitado, pero que retrata desde una mirada ensoñadora y mediante el uso de colores vivos, se aleja la cotidianeidad.

Bergoeing hizo ver que su trabajo pictórico se vincula directamente a su trabajo como geomorfólogo, tanto por la observación y el análisis de los paisajes como por su cartografía. De la misma manera, Juan Carlos Camacho, en su obra, nos introduce a una mirada de los paisajes rurales desde su cartografía con su obra "Paisaje de siempre II" (1994). 


\section{Surrealismo nacional: el contrapunto}

La tentación de tocar algo que ya no es ni el árbol ni el paisaje y poderlo representar, atrapándolo en otra dimensión que finalmente no todos pueden llegar a comprender. El arte surrealista tiene sus raices en el profundo vinculo entre el sueño y la imagen; más que un movimiento, es catalogado por muchos una actitud ante la vida. Lleno de simbolos y referencias al mundo real muy dificiles de identificar, casi es pura creación fantástica.

Foto 4 . La artista Luisa Gonzánez de Sáenz formó parte del grupo de paisajistas costa(1999). "Caballos de las los demás por la creación de una atmósfera austera compuesta de una parata (1969. "Caballos de las" los demás por la creación de una atrós runas" colores pálidos que hacen referencia a la tierra, ella supo aprovechar el plano del Recuperadode clienzo co

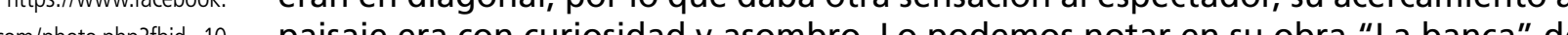

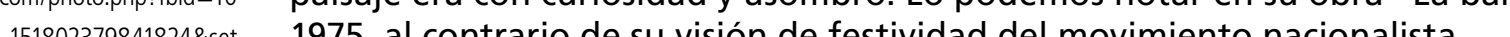

315550818238

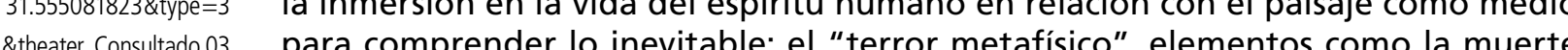
de Mejo 2015. y la soledad que aparecen o se manifiestan en las obras "En el bosqu" (1970) y

"Conversabis "En el bosque" (1970)

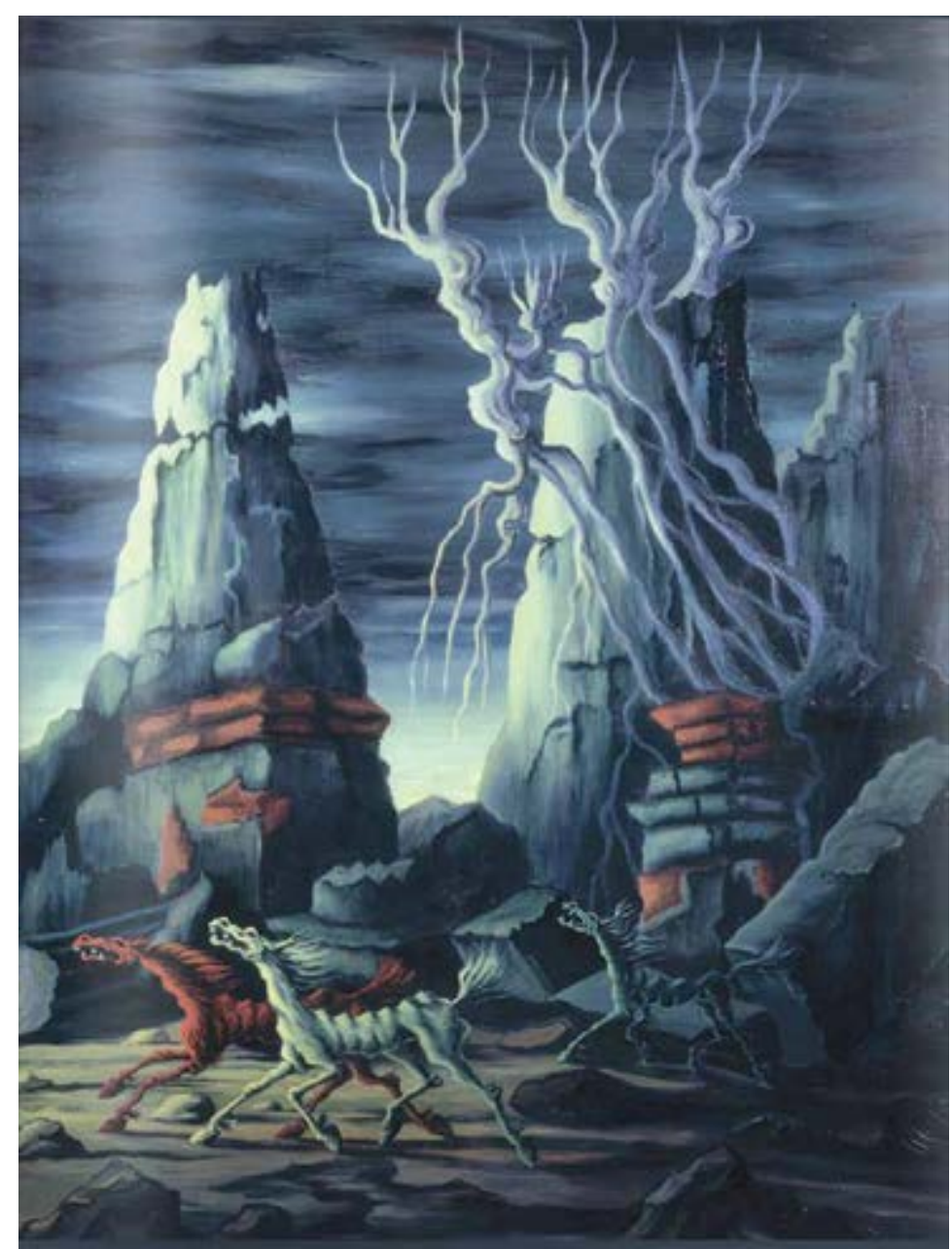
"Conversación en la laguna" de 1978. Luisa González representa nacionales, punto en la pintura nacional semejante al que representó el Barroco en renacimiento. "Caballos de las Ruinas" de 1969 es un ejemplo claro del carácde 1969 es un ejemplo claro del carácOtros artistas surrealistas, que pode mos consideras surrealistas, que podemos considerar, y algunas de sus obras ron Wong con: "La luna de soethoven con volcán llorando" de 1992; Paulin con volcán llorando" de 1992; Paulina 1995 y rripó mágico" de 1995.

\section{La percepción}

\section{ambiental}

Actualmente, dentro del ordenamiento territorial y el diseño de sitio (paisajístico), la percepción y estética del paisaje juegan una importante labor, de esta percepción depende la conservación y restauración de los recursos naturales. El movimiento moderno ecológico en este país, surge de la lucha por la preservación de la diversidad natural que componen nuestros paisajes.
El estilo hiperrealista, utilizado en la actualidad, ha tenido exclusivamente el fin de promover la toma de conciencia sobre la conservación y preservación de las especies y su hábitat natural, y de especies amenazadas de la flora y la fauna, retratándolos fielmente. La obra pictórica actual exalta la belleza de la propia especie y de su entorno propio.

Así, nos encontramos ante una variante del tema que debería ser tomado en cuenta: el fenómeno turístico y la percepción por parte de las personas de los paisajes de otras culturas, la sobreexplotación de la imagen causa trastornos, debido a la sustitución de información, cuando se crean lugares basados en estereotipos e idealizaciones, muchas veces difundidos por los "mass media "la televisión, prensa ión de las personas.

\section{Nota}

1. Trabajo realizado para el curso análisis del paisaje el segundo semestre del año 2013 de la maestría de Paisajismo y Diseño de Sitio de la Universidad de Costa Rica.

\section{Bibliografía}

Floria B. María G. (2003) La pintura a la acuarela en Costa Rica \#11. San José: Editorial de la Universidad de Costa Rica.

Camacho, J. A.. (1982). El estilo en los cuentos de Salazar Herrera. San José: Editorial Universitaria Centroamericana.

Doriam Díaz. (2005). Exposición muestra lo menos conocido de Fausto Pacheco. 11/06/2015, de La Nacion Sitio web: http://wvw.nacion.com/ln_ee/2005/octubre/05/aldea0.html

Fundación Museos Banco Central. (2005). Felo Garcia: Arista, gestor, provocador, innovador. San José: Editorial de la Universidad de Costa Rica.

García lleana, (2011). Felo García: Arista, gestor, provocador, innovador. Editorial de la Universidad de Costa Rica.

Martinéz, M. (2008). Descripciones de jardines y paisajes en la literatura griega antigua. España: Estudios Griegos y Europeos de la Universidad Complutense de Madrid.

Quesada, Florencia. (2011). La modernización entre cafetales San José, Costa Rica, 1880-1930. San José: Editorial de la Universidad de Costa Rica.

Alain, Roger. (2007). Breve Tratado del paisaje. Edición Javier Maderuelo. S. L., Madrid: Editorial biblioteca nueva. 
Rojas, José Miguel. (2008). "Crítica a exposición: Adentro/Afuera". Red cultura. San José.

Lyra, Carmen. (2011). La narrativa de Carmen Lyra, Relatos escogidos. Prólogo de Isabel Ducca D. San José: Editorial Costa Rica.

Sáenz, Guido. (2009). Una mirada risueña a lo terrible / Luisa González de Sáenz. 1.a Edición San José: Litografía e imprenta LIL.

Varios artistas (1996). "Catalogo de artistas plásticos de Costa Rica", San José, C.R, editorial Artdirecto S. A.

varios. (2006). Biografía Teodorico Quirós. 11/06/2015, de vichitex Sitio web: http:// www.vichitex.com/arte/historia_cr/p_teodorico_quiros_bio.htm 